\title{
SURTO DE Salmonella enteritidis/Enteridis EM GRANJA PRODUTORA DE FRANGO CAIPIRA NA REGIÃO SUL DO MARANHÃO
}

\section{Salmonella enteritidis/Enteridis outbreak in a broiler house producer of free-range chickens in south of Maranhão state, Brazil}

\author{
PIGATTO, C.P. ${ }^{1}$; BAPTISTA, F. ${ }^{1}$; FINI, M.B. ${ }^{1}$; SCHOCKEN-ITURRINO, R.P. ${ }^{2}$ \\ 1 Universidade Federal do Tocantins (UFT - Campus Araguaína). \\ ${ }^{2}$ Universidade estadual Paulista (UNESP - Campus Jaboticabal). \\ Endereço para correspondência: Caroline Peters Pigatto: carolinepigatto@yahoo.com.br
}

\section{RESUMO}

Este estudo teve como objetivo detectar o agente responsável pelo elevado índice de mortalidade de pintainhos em propriedade avícola situada na região sul do Maranhão, bem como determinar a fonte de infecção. Frangos foram necropsiados e análises bacteriológicas de fígado, sangue intracardíaco e ração foram realizadas. As amostras provenientes do sangue intracardíaco, do fígado e da ração inicial apresentaram colônias características de Salmonella. Estas colônias foram submetidas a provas bioquímicas e sorológicas para comprovação do agente. A salmonelose é considerada uma enfermidade importante na avicultura e pode causar graves perdas ambientais e econômicas, além do problema de saúde pública. Este relato ressalta a importância de um bom manejo sanitário e programas de controle e prevenção de doenças nas criações.

Palavras-chave: frango; Salmonella Enteritidis; zoonose

\begin{abstract}
The aim of this trial was to detect the agent that causes high mortality of chickens in a farm in the south of Maranhão, Brazil, as well as determining the infection source. Necropsy of the chickens was done and carried through bacteriological analyses of liver, intracardiac blood and chicken food. The samples taken from the heart blood, liver and initial chicken feed had presented characteristic colonies of Salmonella. These colonies had been submitted to the biochemical and serologic tests for evidence of the patogenicity. Salmonelosis is considered an important disease in the poultry keeping and can cause serious ambient and economic losses, beyond the problem of public health. This paper stands out the importance of a good sanitary handling and programs of control and prevention of illnesses in the animal breeding.
\end{abstract}

Key words: poultry; Salmonella Enteritidis; zoonosis 


\section{INTRODUÇÃO}

As salmonelas estão amplamente difundidas na natureza e a importância da sua disseminação vem sendo muito estudada, principalmente na produção avícola (Silva e Duarte, 2002). Considerada uma zoonose de importância mundial, as salmonelas constituem um vasto grupo dentro da família Enterobacteriaceae. São conhecidos mais de 2500 sorotipos bioquimicamente relacionados, no entanto, 80 a 90 são os mais comuns em casos de infecções nas aves e nos humanos (Berchieri Jr, 2000). Algumas doenças provocadas por este agente são a febre tifóide, paratifóide e a gastrenterite no ser humano, bem como as enfermidades de interesse médico veterinário, como a diarréia dos pintainhos (S. Pullorum), o tifo aviário (S. Gallinarum), o aborto eqüino (S. Abortus-equi) (Pereira e Silva, 2005).

A Salmonella Enteritidis é considerada um patógeno entérico de origem alimentar mais freqüentemente relacionado nas ocorrências de gastrenterite em seres humanos. Sua estreita relação com os lotes de frango de corte e suas implicações na saúde pública justifica contínuos estudos (Gast, 2003).

Apesar de a salmonelose possuir elevada prevalência na avicultura industrial (OIE,2004), o agente não é reconhecido a menos que um cuidadoso programa de controle seja efetuado (Silva, 1989; Snoeyenbos, 1991). As três maiores fontes de transmissão para aves de interesse comercial são a introdução de lote contaminado, o ambiente e a ração contaminados (Kampelmacher, 1987). O fato do Brasil ser o maior exportador de carne de aves e pela grande exigência dos países importadores, a necessidade de maior controle é reforçada (Back, 2002).

$\mathrm{O}$ objetivo deste trabalho foi investigar a alta mortalidade das aves em uma propriedade da região sul do Maranhão e confirmar a suspeita de salmonelose por meio de testes laboratoriais.

\section{MATERIAL E MÉTODOS}

Foi relatada uma elevada mortalidade de pintainhos em uma granja avícola situada no município de Riachão, Estado do Maranhão. A propriedade possuía mais de 2000 frangos denominados de frangos "caipira melhorado".

O sistema produtivo da propriedade em questão utiliza instalações simples construídas com madeira e palha de babaçu.Tais instalações consistem em um galinheiro e divisões internas destinadas a cada fase de criação: numa parte permanecem os pintainhos e na outra os frangos com mais de dois meses de idade. O local possui ventilação, luminosidade adequada e disponibilidade de água para os animais. O piso é revestido com uma camada de palha (cama) de 5 a $8 \mathrm{~cm}$ de espessura, distribuída de forma homogênea, sendo utilizada sabugo de milho triturado. A remoção e substituição da cama, bem como, o polvilhamento do aviário com cal virgem não era feito com a frequência ideal (ocorria uma vez a cada mês).

Segundo os relatos, cerca de 1000 pintainhos com uma semana de idade, em média, morreram no intervalo de três dias. A taxa de incidência calculada foi de $66,9 \%$. Por sua vez, nos frangos do outro lote, com um mês de idade, não ocorreu a mesma mortalidade. Os animais da granja eram alimentados com ração sem promotores de crescimento (inicial e de engorda). A água fornecida aos animais era de poço e clorada, sendo os bebedouros lavados três vezes ao dia.

Quatro animais jovens pertencentes ao lote com elevada mortalidade, dois frangos adultos e uma amostra da ração inicial foram encaminhados ao Laboratório 
de Microbiologia e Imunologia Veterinária (LAMIVET) da Universidade Federal do Tocantins, Campus Araguaína, para necropsia e análise bacteriológica.

Foram realizadas necropsias, coleta de sangue intracardíaco e análise da ração. Durante a necropsia foram separadas as seguintes amostras: sangue intracardíaco, fígado, coração, conteúdo da moela e intestino.

Foi realizada a impressão dos órgãos em lâmina e esfregaços com sangue intracardíaco. Estas lâminas foram coradas segundo método de Gram. Para isolamento do agente foram separados duas frações do intestino, do conteúdo da moela, frações do fígado e do coração, o sangue intracardíaco e amostra da ração. Este material foi inoculado em tubos contendo caldo Selenito-cistina e caldo Brain Heart Infusion (BHI) e incubados a $37{ }^{\circ} \mathrm{C}$ por 24horas. Após 0 préenriquecimento, as amostras foram semeadas em ágar Salmonella-Shigella (SS) e ágar MacConkey durante 24 a 48 horas a $37^{\circ} \mathrm{C}$ (OIE, 2004; MAPA, 1995). As colônias com características de Salmonella obtidas em placa foram coradas pelo método de Gram e testadas em análises de identificação bioquímica e sorológica.

A sensibilidade dos isolados foi testada segundo o método de Kirby-Bauer (Bauer et al., 1966). Cada cepa foi inoculada em caldo $\mathrm{BHI}$ e após incubação de 24 horas a $37{ }^{\circ} \mathrm{C}$ foram estriadas com auxílio de um suabe em ágar Mueller-Hinton. A placa foi mantida durante cinco minutos a temperatura ambiente e os discos com antibióticos foram distribuídos nas placas e incubados durante 24 horas a $37^{\circ} \mathrm{C}$. Os antimicrobianos testados foram: Amoxicilina/ácido clavulânico (10mg), Ampicilina $(10 \mathrm{mg})$, Cefoxitina $(10 \mathrm{mg})$, Ceftazidima $(10 \mathrm{mg})$, Ceftriaxona $(10 \mathrm{mg})$, Ciprofloxacina (10 mg), Cloranfenicol (5 $\mathrm{mg}$ ), Imipinem (10 mg), Sulfa/trimetoprim (300 mg), Tetraciclina (30 mg), Ácido nalidíxico $(10 \mathrm{mg})$, Gentamicina $(10 \mathrm{mg})$ e
Nitrofurantoína (10 mg). Os resultados foram interpretados pela mensuração das zonas de inibição, e apresentados como resistentes ou sensíveis de acordo com o National Committee for Clinical Laboratory Standards (NCCLS, 2000). As colônias características do gênero Salmonella nesses meios foram submetidas à sorologia no Instituto Adolfo Lutz.

\section{RESULTADOS}

$\mathrm{Na}$ avaliação geral dos animais, alguns apresentaram fezes diarréicas. No exame necroscópico, foi detectado edema subcutâneo, fígado aumentado, friável e congesto, além da presença de muco no intestino. A análise direta da impressão de órgãos ao microscópio evidenciou bastonetes Gram negativos no sangue intracardíaco.

As amostras provenientes do sangue intracardíaco, dos órgãos e da ração inicial apresentaram colônias isoladas suspeitas de Salmonella e com os seguintes resultados nos testes bioquímicos: não houve fermentação da lactose nem da sacarose, fermentação da glicose, produção de gás e $\mathrm{H}_{2} \mathrm{~S}$, indol negativo, utilização do citrato, móvel, não utilizou o malonato e com a prova do vermelho de metila positiva e Voges-Proskauer negativa. Estes resultados são compatíveis com o gênero Salmonella. A cepa proveniente do sangue intracardíaco apresentou aglutinação frente ao antígeno somático e flagelar e a tipificação realizada no Instituto Adolfo Lutz apresentou aglutinação positiva para Salmonella Enteritidis.

O perfil de sensibilidade a antibióticos e quimioterápicos foi o seguinte: sensível a: Amoxacilina/Ac.clavulânico, Ampicilina, Cefoxitina, Ceftazidima, Ceftriaxona, Ciprofloxacina, Cloranfenicol, Imipinem, Sulfa/Trimetoprim, Tetraciclina e resistente a: Ácido nalidíxico, Gentamicina e Nitrofurantoína. 


\section{DISCUSSÃO}

O mercado consumidor de carnes está cada vez mais exigente, por esta razão, a criação de frangos caipiras, tratados sem promotores de crescimento, está em expansão no País (Demattê Filho e Mendes, 2001). Esse sistema de criação, normatizado pelo Ministério da Agricultura, Pecuária e Abastecimento, é classificado nos padrões do Sistema Caipira/Colonial de produção de aves de corte, via ofício circular DOI/DIPOA n. 007/99 de 19/05/1999. As aves devem ter acesso à área externa e a alimentação tem que ser exclusivamente de fontes vegetais. É proibido o uso de promotores de crescimento de qualquer tipo ou natureza, e a ave não pode receber produtos quimioterápicos e ingredientes de origem animal na ração (Figueiredo et al., 2001).

Tanto na criação de frango caipira quanto na criação industrial, a presença de microrganismos patogênicos nos animais e a possível contaminação de sua carcaça são aspectos importantes em termos de sanidade animal e de saúde pública (Moreno et al., 2006). As principais bactérias que podem representar risco ao consumidor e que têm sido objeto de atenção em programas internacionais de vigilância são Salmonella, Escherichia coli, Campylobacter e Enterococcus (Xavier et al., 2008).

A salmonelose é considerada uma enfermidade importante na avicultura e pode causar graves perdas ambientais e econômicas, além do problema de saúde pública (Trawinska et al., 2008). A infecção por Salmonella em animais jovens ou adultos sensíveis resulta da multiplicação bacteriana no intestino e invasão da corrente sanguínea. O quadro clínico, geralmente, inicia com infecção entérica que pode subsequentemente generalizar após a entrada do organismo na circulação sanguínea, desencadeando uma septicemia (Berchieri Jr, 2000). A coloração de
Gram realizada diretamente no sangue intracardíaco e na impressão dos órgãos destes animais objetivou a análise presuntiva da presença de bactérias no sangue sugerindo uma septicemia.

Os pintainhos envolvidos no surto amontoaram-se perto da fonte de calor, apresentaram-se sonolentos, com diarréia, morrendo em poucas horas. A ração pode ser considerada uma das fontes de infecção neste caso, pois foram isoladas colônias de Salmonella tanto dos órgãos dos animais, do sangue intracardíaco e também da ração. A ração contaminada aliada a fatores como a falta de higiene, o aumento populacional, mudança de temperatura, parasitismo, transporte, doenças virais concorrentes predispõem a salmonelose clínica.

O sorotipo encontrado neste surto foi a Salmonella Enteritidis. Esta informação é importante e ao mesmo tempo preocupante, pois no Brasil, o sorotipo relatado como de maior frequência em casos de infecções em seres humanos é a Salmonella Enteritidis (Galán, 2001). A transmissão dessas bactérias aos humanos ocorre através da ingestão de alimentos ou água contaminados com células viáveis de Salmonella. Os alimentos, crus ou mal cozidos, são frequentemente de origem animal, sendo carne de frango e ovos, os mais envolvidos (Trawinska et al., 2008).

Um adequado manejo e higiene do ambiente são fundamentais para a prevenção desta enfermidade. Falhas no manejo como contaminação da ração desencadeiam graves perdas como foi relatado neste caso.

\section{CONCLUSÕES}

A salmonelose causa graves problemas não só na avicultura industrial, mas também em criações alternativas como de frango caipira. Este relato ressalta a importância de um bom manejo e 
adequadas condições sanitárias na criação.

\section{REFERÊNCIAS}

BACK, A. Manual de Doenças de Aves. Cascavel: 2002, 246p.

BAUER, A.W.; KIRBY, W.M.M.; SHERRIS, J.C. et al. Antibiotic susceptibility testing by a standardized single disk method. American Journal Clinic Pathology, v.45, p.493-496, 1966.

BERCHIERI Jr., A. Salmonelose Aviária. In: BERCHIERI JR,A; MACARI, M. Doença das Aves. Campinas: FACTA, 2000. p.185-196.

DEMATTÊ FILHO, L.C.; MENDES, C.M.I. Viabilidade técnica e econômica na criação alternativa de frangos. In: CONFERÊNCIA APINCO DE CIÊNCIA E TECNOLOGIA AVÍCOLA, 2., 2001, Campinas. Anais... Campinas: FACTA, 2001. p.255-266.

GALÁN, J.E. Salmonella interactions with host cells: type III secretion at work. Annual Review of Cell and Developmental Biology, v.17, p.53-86, 2001.

FIGUEIREDO, E.A.P.; PAIVA, D.P.; ROSA, P.S. et al. Diferentes denominações e classificação brasileira de produção alternativa de frangos. In: CONFERÊNCIA APINCO DE CIÊNCIA E TECNOLOGIA AVÍCOLA, 2., 2001. Campinas. Anais... Campinas: FACTA, 2001, p.209-222.

GAST, R. K. Salmonella Infections. In: SAIF, Y. M. Diseases of Poultry, 11ed. lowa State University Press, p.567-599, 2003.

KAMPELMACHER, E.H. Poultry disease and public healt. Brazilian Poultry Science, v.28, p.3-13, 1987.

\section{MINISTÉRIO DA AGRICULTURA PECUÁRIA E} ABASTECIMENTO. Programa Nacional de Sanidade Avícola (PNSA). Portaria número 126 de 03 de novembro de 1995: normas de credenciamento e monitoramento de laboratórios de diagnóstico das salmoneloses aviárias.

MORENO,M.R.F.; SARANTINOPOULOS, P.; TSAKALIDOU,E. The role and application of enterococci in food and health. International Journal of Food Microbiology, v.106, p.1-24, 2006.
NATIONAL COMMITTEE FOR CLINICAL LABORATORY STANDARDS (NCCLS): Methods for dilution antimicrobial susceptibility tests for bacteria that grow aerobically, Wayne, Pensylvania, 2000.

OIE (Escritório Internacional de Epizootias).

Salmonellosis. Manual of diagnostic tests and vaccines for terrestrial animails, 5ed, 2004.

Disponível em:

<http://www.oie.int/eng/normes/mmanual/A_00129. $\mathrm{htm}>$. Acesso em: 03/05/10.

PEREIRA,M.S.; SILVA,P.L. Prevalência de anticorpos contra Salmonella pullorum e identificação bacteriológica de Salmonella sp em galinhas "caipiras" em Uberlândia (MG). Guia Avicultura Industrial, v.6, p.22-23, 2005.

SILVA, J.M.L. Salmonelose aviária. In: ENCONTRO EMPRESARIAL DE ATUALIZAÇÃO EM

PATOLOGIA AVÍCOLA - SALSBURY, 1989, Campinas. Anais... Campinas: FACTA. 1989. p.5969.

SILVA, E.N.; DUARTE, A. Salmonella Enteritidis em aves: Retrospectiva no Brasil. Revista Brasileira de Ciências Avícola, v.4, n.2, p.85-100, 2002.

SNOEYENBOS, G.H. O presente e o futuro do controle de Salmonella em aves. In: CONGRESSO BRASILEIRO DE AVICULTURA, 12., 1991, Brasília. Anais... Brasília: CBA,1991. p.59-69.

TRAWINSKA, B.; SABA, L., WDOWIAK, L.et al. Evaluation of Salmonella rod incidence in poultry in the Lublin Province over the years 2001-2005. Annals of Agricultural and Environmental Medicine, v.15, p.131-134, 2008.

XAVIER, D.B.; BERNAL, F.E.M.; ALMEIDA, R.T. Prevalência de enterococos isolados de frangos caipiras em diferentes regiões do Distrito Federal. Arquivo Brasileiro de Medicina Veterinária e Zootecnia, v.60, n.6, p.1550-1553, 2008. 